\title{
Early Onset Depression Has Different Characteristics from Middle-Aged Depression in Terms of Circadian Rhythm
}

\author{
Jaegwon Jeong ${ }^{1,2}$, Yujin Lee ${ }^{1,2}$, Chul-Hyun Cho ${ }^{1,2}$, and Heon-Jeong Lee ${ }^{1,2,3}$ \\ Departments of ${ }^{1}$ Psychiatry, ${ }^{3}$ Biomedical Science, Korea University College of Medicine, Seoul, Korea \\ ${ }^{2}$ Chronobiology Institute, Korea University, Seoul, Korea
}

\begin{abstract}
Objective: The aim of this study was to identify the unique biological and circadian rhythmic characteristics of patients with early-onset depression compared to patients with middle-age-onset depression. Methods: A total of 240 subjects were recruited in the study and divided into three groups: healthy young individuals, patients with early-onset depression, and middle-aged patients with unipolar depression. Patients then filled out questionnaires related to biological rhythm disturbances, mood symptoms, diurnal preference, and seasonality. Results: Patients with early-onset depression had significantly different clinical features in terms of mood disorders, diurnal preference, and biological rhythm disturbances compared to middle-aged patients with unipolar depression. Conclusion: Results of this study suggest that early-onset depression is different from middle-age-onset unipolar depression but similar to bipolar disorder.
\end{abstract}

Key Words: Circadian rhythm; Depression; Bipolar disorder

Received: March 1, 2020 Accepted: March 7, 2020

Corresponding author: Heon-Jeong Lee, MD, PhD, Department of Psychiatry, Korea University College of Medicine, 73 Goryeodae-ro, Seongbuk-gu, Seoul 02841, Korea. Tel: 82-2-920-5815, Fax: 82-2-929-7679, E-mail: leehjeong@korea.ac.kr

@ This is an Open Access article distributed under the terms of the Creative Commons Attribution Non-Commercial License (https://creativecommons.org/licenses/by$\mathrm{nc} / 4.0$ ) which permits unrestricted non-commercial use, distribution, and reproduction in any medium, provided the original work is properly cited.

\section{INTRODUCTION}

Despite bipolar disorder being a major debilitating mental illness, approximately $60 \%$ of patients with bipolar disorder are initially diagnosed with major depressive disorder (MDD) [1,2]. Some studies revealed that many people diagnosed with depression have bipolar disorder, most of whom are not diagnosed as being bipolar [3-5]. In particular, a study demonstrated that $27 \%$ of patients initially diagnosed with depressive disorder developed hypomanic episodes while $19 \%$ of patients developed full bipolar manic episodes [6]. Misdiagnosing a patient with bipolar disorder experiencing a depressive episode as having unipolar depression may cause several negative consequences, including inappropriate pharmacological prescriptions [7].

Several demographic and clinical characteristics are common between bipolar disorder and unipolar depression, including an early onset of illness (early 20s) and seasonality [8]. The Mood Disorder Questionnaire (MDQ) is a widely used screening instrument for bipolar disorder in patients with depression [9]. Emerging evi- dences suggest that circadian rhythm dysregulations could be a unique pathogenetic mechanism in bipolar disorder [10-17]. In particular, evidences suggest that acute mood episodes in bipolar disorder are related to circadian misalignment [14].

Biological rhythm is a concept that comprehends cyclic variations of both physiological and behavioral functions [18]. The Biological Rhythms Interview of Assessment in Neuropsychiatry (BRIAN) is a validated instrument that assesses the four main areas of circadian rhythm disturbance in bipolar disorder, namely sleep, social rhythm, activity, and eating pattern [19]. Previous studies reported that biological rhythmic disturbances in subjects with bipolar disorder can be considered as a trait marker of the disease $[19,20]$ and also a trait for distinguishing bipolar disorder from MDD [21-23].

The purpose of this study was to identify and better understand the unique characteristics of early-onset depression by comparing the self-reported biological rhythms of patients with early-onset depression with those of patients with middle-age-onset MDD. 


\section{METHODS}

\section{Participants}

A total of 240 participants were recruited in the study and divided into three groups: early-onset MDD (eMDD), late-onset $\mathrm{MDD}$ (IMDD), and healthy control (HC) groups. The eMDD group comprised 165 individuals with early-onset depression as part of the Mood Disorder Cohort Research Consortium study (ClinicalTrials.gov: NCT03088657) [24]. These patients were either under 35 years of age and had completed less than 2 years of treatment or under 25 years of age and had been diagnosed with MDD using the Mini-International Neuropsychiatric Interview [25]. The IMDD group comprised 35 patients diagnosed with MDD according to the Diagnostic and Statistical Manual of Mental Disorders, Fifth Edition [26] and either aged over 35 years with over 2 years of treatment or aged over 45 years. These patients were recruited from the psychiatry outpatient clinic of the Korea University Hospital. The HC group comprised 40 individuals recruited from the general population of young adults [27]. All study participants were informed in detail about the purpose and procedures of the study prior to signing an informed consent form. The study protocol was approved by the Institutional Review Board of the Korea University Hospital (IRB No: 2018AN0446) and was conducted in accordance with the Declaration of Helsinki.

\section{Assessments}

All 240 participants were evaluated using clinical scales, including the Korean version of BRIAN, Korean version of MDQ [28], Korean version of Morningness-Eveningness Questionnaire (MEQ) [29], Korean Self-Rating Version of the Quick Inventory of Depressive Symptomatology (QIDS) [30], and Korean translation of the Seasonal Pattern Assessment Questionnaire [31]. Furthermore, sociodemographic characteristics of participants at the first visit were recorded. MEQ is a questionnaire for evaluating diurnal preference (also referred to as chronotype or morningnesseveningness trait). Patients with a higher MEQ score were considered to have increased morningness, reflecting earlier peaks in diurnal activity and energy and an advanced sleep-wake cycle. We investigated seasonal variations with the global seasonality score (GSS), a sum score of the degree (0-4) of seasonal variation of six items: sleep length, social activity, mood, energy level, body weight, and appetite, ranging from 0 to 24 . A higher GSS indicates higher seasonal variations, which implies a higher possibility of having seasonal affective disorder, also known as winter depression [31].

\section{Statistical Analysis}

Statistical analyses were carried out with SPSS, version 22.0, for Windows (IBM Corp., Armonk, NY, USA). Comparison of sociodemographic and clinical variables between three groups was performed using the chi-square test and analysis of variance (ANOVA), followed by a pairwise comparison using Scheffe's method. In case of unequal variances, Welch's test and Dunnett
T3 test were performed in three-group comparisons, followed by a pairwise comparison with ANOVA and Scheffe's method, respectively. We performed Pearson's correlation test for the correlation analysis of the age and total BRIAN score in the IMDD group. Results of the analysis were considered at a nominal significance of $\mathrm{p}<0.05$.

\section{RESULTS}

Demographic and Clinical Characteristics of Participants

Among the total 240 participants, 40, 35, and 165 were in the HC, IMDD, and eMDD groups, respectively. Table 1 shows the demographic and clinical characteristics of the sample. Patients in the IMDD group were older than those in the HC or eMDD group based on the inclusion criteria. Females accounted for a larger proportion of the IMDD group compared to the HC or eMDD group. Participants in the HC group had more years of education compared to those of other groups.

All clinical variables (MDQ, QIDS, MEQ, and GSS) investigated in this study showed significant differences in the three-group comparison. In the subgroup analysis, the eMDD group showed significant differences in MDQ, QIDS, and MEQ results compared to the IMDD group. Only GSS showed no significant difference between the eMDD and IMDD groups. The HC and IMDD groups showed no significant difference in the MDQ or MEQ score. The eMDD group showed a significant difference in $\mathrm{MDQ}$, QIDS, and MEQ results and GSS compared to the HC group.

\section{Differences of Biological Rhythms between eMDD and IMDD Groups}

The total BRIAN score and all five subscales showed significant differences among the three groups. In the subgroup analysis, the eMDD group had significantly higher total BRIAN score and scores of two subscales (social activity, eating pattern) than the IMDD group. Significant differences were found in the total score and scores of all subscales between the eMDD and HC groups. In eating and chrono subscales, the IMDD group scored higher than the HC group, but without statistical significance.

We checked the correlation of the total BRIAN score and age in the lMDD group since the age range in the lMDD group was relatively wide and evenly distributed. Age in the IMDD group ranged from 40 to 77 years, and the correlation coefficient $r$ with the total BRIAN score was $-0.073(\mathrm{p}=0.661)$. This result has not been displayed in the table.

\section{DISCUSSION}

According to the current diagnostic criteria, individuals with early-onset depression without apparent manic or hypomanic symptoms may be diagnosed with unipolar depression, also called MDD. However, we expected that a significant proportion of patients in the eMDD group could undergo bipolar conversion. In contrast, individuals in the IMDD group are supposed to be con- 
Table 1. Comparison of clinical and biological rhythmic characteristics between patients with eMDD, patients with IMDD, and HC based on questionnaire answers

\begin{tabular}{|c|c|c|c|c|c|}
\hline & $\mathrm{HC}$ group $(\mathrm{n}=40)$ & lMDD group $(\mathrm{n}=35)$ & eMDD group $(n=165)$ & $\mathrm{p}$-value & Post-hoc comparison \\
\hline Age (yr) & $24.1 \pm 3.14$ & $56.7 \pm 9.87$ & $22.7 \pm 3.67$ & $<0.001^{\dagger}$ & eMDD, $\mathrm{HC}<1 \mathrm{MDD}$ \\
\hline Sex & & & & $0.015^{*}$ & \\
\hline Male & $20(50)$ & $8(22.9)$ & $81(49.1)$ & & \\
\hline Female & $20(50)$ & $27(77.1)$ & $84(50.9)$ & & \\
\hline Years of education & $15.7 \pm 1.00$ & $12.4 \pm 3.65$ & $13.6 \pm 2.10$ & $<0.001^{\dagger}$ & IMDD, eMDD $<\mathrm{HC}$ \\
\hline MDQ & $3.25 \pm 3.20$ & $4.49 \pm 3.32$ & $6.09 \pm 3.33$ & $<0.001^{\dagger}$ & $\mathrm{HC}, \mathrm{lMDD}<\mathrm{eMDD}$ \\
\hline QIDS & $3.50 \pm 3.14$ & $14.2 \pm 6.72$ & $17.4 \pm 8.14$ & $<0.001^{\dagger}$ & $\mathrm{HC}<\mathrm{lMDD}<\mathrm{eMDD}$ \\
\hline MEQ & $32.6 \pm 6.34$ & $33.6 \pm 7.46$ & $27.7 \pm 6.95$ & $<0.001^{\dagger}$ & $\mathrm{eMDD}<\mathrm{HC}, \mathrm{lMDD}$ \\
\hline GSS & $8.15 \pm 2.83$ & $10.6 \pm 2.95$ & $10.8 \pm 4.90$ & $<0.001^{\dagger}$ & $\mathrm{HC}<\mathrm{lMDD}$, eMDD \\
\hline BRIAN & $29.1 \pm 8.14$ & $38.1 \pm 11.1$ & $44.5 \pm 11.8$ & $<0.001^{\dagger}$ & $\mathrm{HC}<\mathrm{lMDD}<\mathrm{eMDD}$ \\
\hline Sleep & $9.25 \pm 2.62$ & $12.5 \pm 3.62$ & $13.5 \pm 3.88$ & $<0.001^{\dagger}$ & $\mathrm{HC}<\mathrm{lMDD}$, eMDD \\
\hline Activity & $7.15 \pm 2.38$ & $10.5 \pm 4.59$ & $11.6 \pm 4.01$ & $<0.001^{\dagger}$ & $\mathrm{HC}<\mathrm{lMDD}$, eMDD \\
\hline Social & $5.63 \pm 1.93$ & $7.06 \pm 2.50$ & $9.18 \pm 3.21$ & $<0.001^{\dagger}$ & $\mathrm{HC}<\mathrm{lMDD}<\mathrm{eMDD}$ \\
\hline Eating & $7.05 \pm 2.59$ & $8.00 \pm 3.43$ & $10.2 \pm 3.58$ & $<0.001^{\dagger}$ & $\mathrm{HC}, \mathrm{lMDD}<\mathrm{eMDD}$ \\
\hline Chronotype & $5.90 \pm 1.43$ & $6.66 \pm 1.55$ & $6.99 \pm 1.61$ & $<0.001^{\dagger}$ & $\mathrm{HC}<\mathrm{eMDD}$ \\
\hline
\end{tabular}

Data are expressed as mean \pm standard deviation or number $(\%) .{ }^{*} \mathrm{p}<0.05,{ }^{\dagger} \mathrm{p}<0.001$. HC: healthy control, lMDD: late-onset major depressive disorder, eMDD: early-onset major depressive disorder, MDQ: Mood Disorder Questionnaire, QIDS: Quick Inventory of Depressive Symptomatology, MEQ: Morningness-Eveningness Questionnaire, GSS: General Seasonality Score, BRIAN: Biological Rhythms Interview of Assessment in Neuropsychiatry

firmed with unipolar depression in relation to their age and treatment duration.

Results from the analysis implied that the eMDD group had unique characteristics compared to the IMDD and HC groups. In particular, the eMDD group had more disturbances in biological rhythms than the IMDD group, particularly in social activity and eating patterns. Influences of age on biological rhythmic disturbances is still not well-known. Nevertheless, in our IMDD group, the total BRIAN score did not correlate with age. In addition, the mean total BRIAN score in the middle-aged control group of a large multi-center study [32] conducted at three locations (Spain, Brazil, and Canada) was similar to that in the young-age control group in our study.

Moreover, the mean total BRIAN score of bipolar II disorder in previous studies conducted in Korea $[27,33]$ was close to that of the eMDD group in our study. However, there is no cut-off BRIAN score distinguishing bipolar disorder from MDD, and most individuals in the eMDD group demonstrated a significant amount of biological rhythmic disturbances similar to those with bipolar II disorder.

The MDQ score was also higher in the eMDD group than in the IMDD group. The best cut-off MDQ score was 6 or 7, distinguishing between bipolar disorder and MDD [34]. This also implies the heterogeneous nature of the eMDD group composed of pure unipolar depression and bipolar disorder.

Interestingly, the MEQ score of the eMDD group was significantly lower than both $\mathrm{MDD}$ and HC groups, which implies increased eveningness in the eMDD group. One possible explanation is that individuals in the eMDD group are susceptible to circadian phase delay, thus having more chances of circadian misalignment leading to disturbances in biological rhythms and even depressive episodes. Next, we could suppose that susceptibility to circadian phase delay following disturbances in biological rhythms, seasonality, an early age of onset, and frequently recurrent depressive episodes are common characteristics shared by patients with early-onset depression and patients with bipolar II disorder but not those with typical middle-age-onset unipolar depression.

The main limitation of our study was the relatively small number of individuals in the HC and IMDD groups. Moreover, participants in the $\mathrm{HC}$ group were young and age distribution was narrow (mean age: $24.1 \pm 3.14$ years). Nevertheless, the relationship between BRIAN and aging was not well established, but in our sample, age was not related to the BRIAN score.

In this study, we demonstrated distinguishable biological rhythmic features of patients with early-onset depression. Compared to typical patients with middle-age-onset unipolar depression, those with early-onset depression have similar aspects to patients with bipolar II disorder. In particular, the eMDD group scored higher on MDQ and had higher disturbances in biological rhythmicity in the BRIAN questionnaire compared to the IMDD group.

Furthermore, the unique characteristics of the eMDD group can be explained by the circadian rhythm hypothesis of bipolar disorder in that they are similar to the characteristics of bipolar disorder. Our results suggest alternative ways to understand early-onset depression, which can lead to appropriate diagnosis and treatment.

\section{Acknowledgments}

This study was supported by the Korea Health 21 R\&D Project funded by the National Research Foundation of Korea (2017M3A9F1031220 and 2019R1A2C2084158). 


\section{Conflicts of Interest}

The authors have no potential conflicts of interest to disclose.

\section{Author Contributions}

Conceptualization: Heon-Jeong Lee. Formal analysis: HeonJeong Lee, Chul-Hyun Cho, Yujin Lee, Jaegwon Jeong. Funding acquisition: Heon-Jeong Lee. Investigation: Heon-Jeong Lee, Chul-Hyun Cho, Yujin Lee, Jaegwon Jeong. Methodology: HeonJeong Lee, Jaegwon Jeong. Project administration: Heon-Jeong Lee. Resources: Heon-Jeong Lee. Supervision: Heon-Jeong Lee, Chul-Hyun Cho, Yujin Lee. Software: Heon-Jeong Lee. Validation: Heon-Jeong Lee, Chul-Hyun Cho, Yujin Lee, Jaegwon Jeong. Visualization: Jaegwon Jeong. Writing_original draft: Jaegwon Jeong. Writing - review \& editing: Heon-Jeong Lee, Chul-Hyun Cho, Yujin Lee, Jaegwon Jeong.

\section{ORCID iDs}

Heon-Jeong Lee (1)

https://orcid.org/0000-0002-9560-2383

Jaegwon Jeong (1)

https://orcid.org/0000-0003-1152-833X

\section{REFERENCES}

1. Hirschfeld RM, Lewis L, Vornik LA. Perceptions and impact of bipolar disorder: how far have we really come? Results of the national depressive and manic-depressive association 2000 survey of individuals with bipolar disorder. J Clin Psychiatry 2003;64:161-174.

2. Hirschfeld RM, Vornik LA. Bipolar disorder--costs and comorbidity. Am J Manag Care 2005;11(3 Suppl):S85-S90.

3. Benazzi F. Prevalence of bipolar II disorder in outpatient depression: a 203case study in private practice. J Affect Disord 1997;43:163-166.

4. Hirschfeld RM, Cass AR, Holt DC, Carlson CA. Screening for bipolar disorder in patients treated for depression in a family medicine clinic. J Am Board Fam Pract 2005;18:233-239.

5. Hirschfeld RM, Calabrese JR, Weissman MM, Reed M, Davies MA, Frye MA, et al. Screening for bipolar disorder in the community. J Clin Psychiatry 2003;64:53-59.

6. Goldberg JF, Harrow M, Whiteside JE. Risk for bipolar illness in patients initially hospitalized for unipolar depression. Am J Psychiatry 2001;158: 1265-1270.

7. Hirschfeld RM. Differential diagnosis of bipolar disorder and major depressive disorder. J Affect Disord 2014;169 Suppl 1:S12-S16.

8. Goodwin FK, Jamison KR. Manic-depressive illness: bipolar disorders and recurrent depression. 2nd ed. New York: Oxford University Press; 2007.

9. Hirschfeld RM, Williams JB, Spitzer RL, Calabrese JR, Flynn L, Keck PE Jr, et al. Development and validation of a screening instrument for bipolar spectrum disorder: the Mood Disorder Questionnaire. Am J Psychiatry 2000;157:1873-1875.

10. Lee HJ, Son GH, Geum D. Circadian rhythm hypotheses of mixed features, antidepressant treatment resistance, and manic switching in bipolar disorder. Psychiatry Investig 2013;10:225-232.

11. Takaesu Y. Circadian rhythm in bipolar disorder: a review of the literature. Psychiatry Clin Neurosci 2018;72:673-682.

12. Wood J, Birmaher B, Axelson D, Ehmann M, Kalas C, Monk K, et al. Replicable differences in preferred circadian phase between bipolar disorder patients and control individuals. Psychiatry Res 2009;166:201-209.

13. Giglio LM, Magalhães PV, Andersen ML, Walz JC, Jakobson L, Kapczinski F. Circadian preference in bipolar disorder. Sleep Breath 2010;14:153-155.

14. Moon JH, Cho CH, Son GH, Geum D, Chung S, Kim H, et al. Advanced circadian phase in mania and delayed circadian phase in mixed mania and depression returned to normal after treatment of bipolar disorder. EBioMedicine 2016;11:285-295.

15. Bauer M, Grof P, Rasgon N, Bschor T, Glenn T, Whybrow PC. Temporal relation between sleep and mood in patients with bipolar disorder. Bipolar Disord 2006;8:160-167.

16. Takaesu Y, Inoue Y, Ono K, Murakoshi A, Futenma K, Komada Y, et al. Circadian rhythm sleep-wake disorders as predictors for bipolar disorder in patients with remitted mood disorders. J Affect Disord 2017;220:57-61.

17. Lee HJ. Circadian misalignment and bipolar disorder. Chronobiol Med 2019;1:132-136.

18. Soria V, Urretavizcaya M. [Circadian rhythms and depression]. Actas Esp Psiquiatr 2009;37:222-232.

19. Giglio LM, Magalhães PV, Andreazza AC, Walz JC, Jakobson L, Rucci P, et al. Development and use of a biological rhythm interview. J Affect Disord 2009;118:161-165.

20. Rosa AR, Comes M, Torrent C, Solè B, Reinares M, Pachiarotti I, et al. Biological rhythm disturbance in remitted bipolar patients. Int J Bipolar Disord 2013;1:6.

21. Mondin TC, Cardoso TA, Souza LDM, Jansen K, da Silva Magalhães PV, Kapczinski F, et al. Mood disorders and biological rhythms in young adults: a large population-based study. J Psychiatr Res 2017;84:98-104.

22. Duarte Faria A, Cardoso Tde A, Campos Mondin T, Souza LD, Magalhaes PV, Patrick Zeni C, et al. Biological rhythms in bipolar and depressive disorders: a community study with drug-naïve young adults. J Affect Disord 2015;186:145-148.

23. Moro MF, Carta MG, Pintus M, Pintus E, Melis E, Kapczinski F, et al. Validation of the Italian version of the Biological Rhythms Interview of Assessment in Neuropsychiatry (BRIAN): some considerations on its screening usefulness. Clin Pract Epidemiol Ment Health 2014;10:48-52.

24. Cho CH, Ahn YM, Kim SJ, Ha TH, Jeon HJ, Cha B, et al. Design and methods of the Mood Disorder Cohort Research Consortium (MDCRC) study. Psychiatry Investig 2017;14:100-106.

25. Sheehan DV, Lecrubier Y, Sheehan KH, Amorim P, Janavs J, Weiller E, et al. The Mini-International Neuropsychiatric Interview (M.I.N.I.): the development and validation of a structured diagnostic psychiatric interview for DSM-IV and ICD-10. J Clin Psychiatry 1998;59 Suppl 20:22-33.

26. American Psychiatric Association. Diagnostic and Statistical Manual of Mental Disorders (DSM-5 ${ }^{\circledR}$ ). Arlington, VA: American Psychiatric Association; 2013.

27. Cho CH, Jung SY, Kapczinski F, Rosa AR, Lee HJ. Validation of the Korean version of the Biological Rhythms Interview of Assessment in Neuropsychiatry. Psychiatry Investig 2018;15:1115-1120.

28. Jon DI, Hong N, Yoon BH, Jung HY, Ha K, Shin YC, et al. Validity and reliability of the Korean version of the Mood Disorder Questionnaire. Compr Psychiatry 2009;50:286-291.

29. Lee JH, Kim SJ, Lee SY, Jang KH, Kim IS, Duffy JF. Reliability and validity of the Korean version of Morningness-Eveningness Questionnaire in adults aged 20-39 years. Chronobiol Int 2014;31:479-486.

30. Hong JP, Park SJ, Park S, Lim A, Jeon D. Reliability and validity study of the Korean Self Rating version of Quick Inventory of Depressive Symptomatology (K-QIDS-SR). Mood Emot 2013;11:44-50.

31. Magnusson A. Validation of the Seasonal Pattern Assessment Questionnaire (SPAQ). Affect Disord 1996;40:121-129.

32. Pinho M, Sehmbi M, Cudney LE, Kauer-Sant'anna M, Magalhães PV, Reinares $\mathrm{M}$, et al. The association between biological rhythms, depression, and functioning in bipolar disorder: a large multi-center study. Acta Psychiatr Scand 2016;133:102-108.

33. Kim SC, Cho CH, Lee Y, Seo JY, Ahn YM, Kim SJ, et al. Similarities of aspects of biological rhythms between major depression and bipolar II disorder compared to bipolar I disorder: a finding from the early-onset mood disorder cohort. Psychiatry Investig 2019;16:829-835.

34. Yang HC, Liu TB, Rong H, Bi JQ, Ji EN, Peng HJ, et al. Evaluation of Mood Disorder Questionnaire (MDQ) in patients with mood disorders: a multicenter trial across China. PLoS One 2014;9:e91895. 